\title{
Ultrasonido en tumores óseos como hallazgo inesperado: Elementos de sospecha y caracterización
}

\author{
Dres. Carolina Whittle $P^{(1)}$, Nicolás Sánchez $D^{(2)}$, Giancarlo Schiappacasse $F^{(3)}$, Valeria Schonstedt $G^{(2)}$, \\ TM. Gina Baldassare $P^{(4)}$. \\ 1. Profesor de Radiología. Facultad de Medicina Clínica Alemana - Universidad del Desarrollo. Departamento Imágenes. \\ Clínica Alemana de Santiago de Chile. \\ 2. Radiólogo. Departamento de Imágenes. Facultad de Medicina Clínica Alemana - Universidad del Desarrollo. Santiago, Chile. \\ 3. Profesor Asociado de Radiología. Facultad de Medicina Clínica Alemana - Universidad del Desarrollo. Departamento \\ Imágenes. Clínica Alemana de Santiago de Chile. \\ 4. Tecnólogo Médico. Departamento Imágenes. Clínica Alemana de Santiago de Chile.
}

\section{Bone tumor lesions: suspected elements and initial characterization of soft tissue in ultrasound.}

\begin{abstract}
Introduction. The swelling of the soft tissues can be studied with a variety of techniques, amongst which the emphasis is on high resolution ultrasound (US) for its high availability. Bone tumors are a very rare cause of increased volume in soft tissue. Before the ultrasound finding of a bone tumor it is important to try to specify their nature to determine the need for additional studies. Objective. To present an ultrasound schema that allows for a better diagnostic approach to the unusual finding of a bone tumor. Method. Retrospective study. All soft tissue ultrasound performed at our institution over a period of five years (2009-2013), were reviewed. Two expert radiologists consensually analyzed the US which demonstrated a bone tumor underlying an increased volume of soft tissue. The series consists of 30 ultrasonographic studies. Results. In all of the cases, the US showed a dermoepidermal complex, of the subcutaneous tissue and the normal aponeurosis plane. In the deep planes altered cortical bone was identified. Complementary studies and in some cases biopsies, allowed us to determine the nature of the evaluated lesions. They corresponded to osteomas, osteochondromas, subungual exostoses, bone hemangioma, brown tumor, enchondroma and bone metastases. It was possible to identify certain ultrasound patterns of the soft tissue bone lesions. We described three patterns which we named: Type I - Raised hyperechoic lesion with acoustic shadowing; Type II - Hypoechoic lesion: IIa, without bone destruction and IIb: with cortical destruction and soft tissue mass; Type III - Presence of irregular periostitis and soft tissue mass. Conclusions. It was possible to recognize an ultrasound pattern of tumors of bone origin. Most cases are benign lesions (osteomas and subungual exostoses) and are presented as Type I. In contrast the Type III pattern suggests aggressiveness and is present in metastatic lesions. In the hypoechoic lesions, the cortical destruction and soft tissue mass suggest aggressiveness (IIb) however the absence of bone destruction and soft tissue mass rather suggests benign processes. These patterns can be useful for radiologists, to make a better diagnostic approach. Keywords: Bone tumors, osteochondromas, osteomas, US.
\end{abstract}

Resumen: Introducción. El aumento de volumen de las partes blandas puede ser estudiado con una variedad de técnicas, entre ellas destaca el ultrasonido de alta resolución (US) por su alta disponibilidad. Los tumores óseos son una causa muy infrecuente de aumento de volumen de partes blandas. Ante el hallazgo ecográfico de una tumoración ósea es importante intentar especificar su naturaleza para determinar la necesidad de estudios complementarios. Objetivo. Presentar un esquema ecográfico que permita una mejor aproximación diagnóstica ante el hallazgo inusual de un tumor óseo. Método. Estudio retrospectivo. Se revisaron todos los US de partes blandas realizados en nuestra institución por un periodo de 5 años (2009-2013). Dos radiólogos expertos analizaron en forma consensual los US que demostraron una tumoración ósea subyacente al aumento de volumen de partes blandas. La serie consta de 30 estudios ultrasonográficos. Resultados. En todos los casos el US mostró un complejo dermo-epidérmico, del tejido subcutáneo y del plano aponeurótico normal. En los planos profundos se identificó una alteración de la cortical ósea. Los estudios complementarios y en algunos casos las biopsias, permitieron determinar la naturaleza de las lesiones evaluadas. Correspondieron a osteomas, osteocondromas, exostosis subungueal, hemangioma óseo, tumor pardo, encondroma y metástasis óseas. Fue posible identificar ciertos patrones ecográficos de las lesiones óseas de partes blandas. Describimos tres patrones que denominamos como: Tipo I.- Lesión elevada hiperecogénica con sombra acústica; Tipo II.- Lesión hipoecogénica: Ila, 
sin destrucción ósea y llb: con destrucción cortical y masa de partes blandas; Tipo III.- Presencia de periostitis irregular y masa de partes blandas. Conclusiones. Fue posible reconocer un patrón ecográfico de las tumoraciones de origen óseo. La mayoría de los casos corresponden a lesiones benignas (osteomas y exostosis subungueal) y se presentan como patrón tipo I. En cambio el patrón tipo III sugiere agresividad y está presente en lesiones metastásicas. En las lesiones hipoecogénicas (II), la destrucción cortical y masa de partes blandas sugieren agresividad (IIb) en cambio la ausencia de destrucción ósea y masa de partes blandas sugiere más bien procesos benignos (Ila). Estos patrones pueden ser de utilidad para los radiólogos, para realizar una mejor aproximación diagnóstica.

Palabras clave: Osteocondromas, Osteomas, Tumores óseos, US.

Whittle C, Sánchez N, Schiappacasse G, Schonstedt V, Baldassare G. Ultrasonido en tumores óseos como hallazgo inesperado: Elementos de sospecha y caracterización. Rev Chil Radiol 2015; 21(3): 100-107.

Correspondencia: Carolina Whittle P. / cwhittlep@gmail.com

Trabajo recibido el 12 de noviembre de 2014. Aceptado para publicación el 12 de agosto de 2015.

\section{Introducción}

Los tumores óseos son lesiones relativamente infrecuentes. Hay múltiples tipos histológicos, pero básicamente estas lesiones se pueden dividir en dos grupos principales: benignas o malignas. La mayoría de los tumores benignos son asintomáticos. La real incidencia permanece desconocida, sin embargo, grandes series han descrito una relación benigno-maligno de $5: 1^{(1)}$. Los tumores malignos corresponden al $1 \%$ del total de neoplasias malignas en humanos ${ }^{(2)}$. En base a los hallazgos de imagen pueden ser descritos como lesiones de alta o baja agresividad.

La presentación clínica varía dependiendo del tipo de tumor. Algunos casos son asintomáticos y son descubiertos en forma incidental. Otros se pueden presentar con un espectro amplio de signos y síntomas, dependiendo de su histología y localización. El aumento de volumen de partes blandas se considera una presentación infrecuente.

En el estudio por imágenes de una masa de partes blandas existen distintas técnicas de diagnóstico, entre ellas la de ultrasonido de alta resolución (US). Encontrar una lesión ósea tumoral, como la causa de esta tumoración, es inusual.

EI US no es un examen de elección en el estudio de tumores óseos pero puede detectar lesiones tumorales óseas no sospechadas clínicamente y ser útil como guía para la realización de biopsias percutáneas.

Nuestro objetivo es presentar, basado en nuestra serie de 30 pacientes, un patrón de los hallazgos en ultrasonido que permitan hacer una aproximación diagnóstica ante el hallazgo incidental de un tumor óseo.

\section{Material y método}

Este estudio fue aprobado por la junta revisora institucional, quienes dispensaron del consentimiento informado, dado su carácter retrospectivo.

Se realizó una búsqueda de las imágenes almacenadas en el sistema Agfa "Pictures Archiving y Communication System" de todos aquellos US de partes blandas realizados en un período de cinco años en nuestra institución, resultando en 2.574 exámenes. Se revisaron todos éstos y se seleccionaron aquellos cuyos informes describen lesiones óseas tumorales, resultando una serie de 30 estudios. Todos ellos se presentaron clínicamente como tumor o aumento de volumen de partes blandas, en su mayoría referidos a nuestro departamento por dermatólogos. Estos exámenes fueron realizados con un equipo Phillips Ultrasound iU22, usando transductores lineales de alta resolución multifrecuenciales de $12-5 \mathrm{MHz}$ y $17-5 \mathrm{MHz}$ y en la mayoría de los casos se usó almohadilla de silicona.

Se revisaron los archivos electrónicos, los estudios imagenológicos complementarios y en algunos pacientes se dispuso de estudios histológicos.

Los hallazgos ultrasonográficos fueron analizaron por dos radiólogos expertos en ultrasonido, en forma consensual, para establecer un esquema de patrones ecográficos que se correlacione con la naturaleza de las lesiones óseas.

\section{Resultados}

En un período de 5 años se estudiaron 30 casos de tumores óseos (17 mujeres y 13 hombres). La edad media fue de 40 años, con un rango de edad entre 1 y 91 años.

En todos los casos, el US demostró el complejo dermo-epidérmico y tejido celular subcutáneo de aspecto normal. El plano aponeurótico presentó el patrón lineal ecogénico normal. En los planos profundos se identificó alteración del plano óseo. La cortical ósea estaba solevantada, destruida o de superficie irregular. Estas alteraciones sugerían una lesión ósea, probablemente de origen tumoral.

Posterior al hallazgo incidental de un tumor óseo al US, a todos los pacientes se les realizó un estudio radiológico convencional y en siete casos, también se realizó una tomografía computada (TC) o resonancia magnética (RM), de acuerdo al hallazgo.

En 25 de los 30 casos (83\%) los estudios complementarios confirmaron su naturaleza benigna: 11 osteomas y 1 osteocondroma (9 mujeres y 3 
hombres, edad media 45 años), principalmente osteomas cráneo/frontales; 10 exostosis subungueal (sin diferencia por género, edad promedio de 27 años), 1 hemangioma frontal, 1 tumor pardo y 1 encondroma del dedo. Cinco de los 30 casos (17\%) fueron lesiones malignas de origen metastásico (confirmadas por biopsia).

De acuerdo a los hallazgos ecográficos de la serie, categorizamos las lesiones en tres patrones ecográficos predominantes:

\section{Tipo I. Lesión hiperecogénica elevada con som- bra acústica.}

la. Lesión hiperecogénica elevada de ángulos obtusos.

La lesión presenta protrusión cortical con superficie ósea continua y sombra acústica hacia la profundidad. El solevantamiento forma ángulos obtusos entre la cortical ósea y las partes blandas adyacentes que están improntadas, pero no alteradas. No hay masa de partes blandas regionales

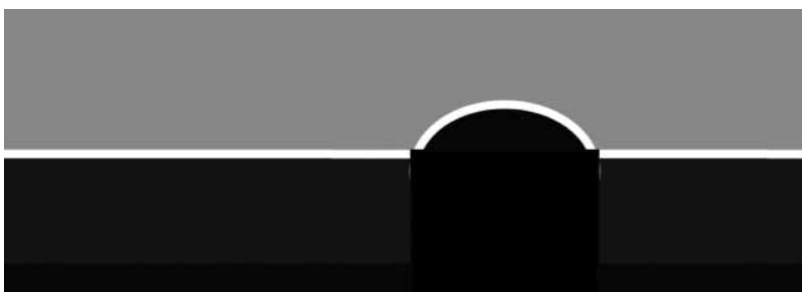

Figura 1. Patrón Tipo la. Esquema. Lesión hiperecogénica elevada con sombra acústica y ángulos obtusos.

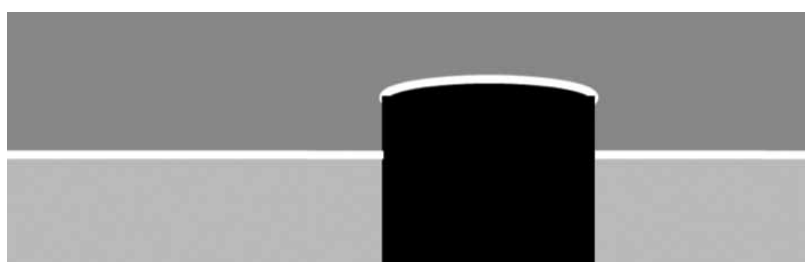

Figura 3. Patrón Tipo Ib. Esquema. Lesión hiperecogénica solevantada de ángulos rectos.

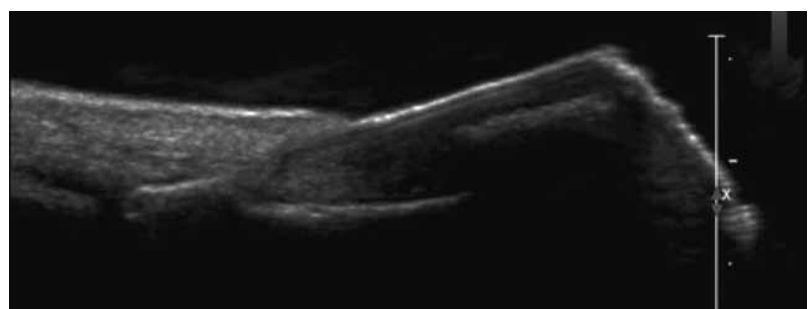

(Figura 1). Este patrón se encontró en 9 de 12 casos de osteomas (Figura 2).

Ib. Lesión hiperecogénica elevada de ángulos rectos. Lesiones de superficie regular con intensa sombra acústica hacia distal. Los bordes de la lesión no se ven continuos con la cortical ósea que es regular. La delimitación lateral de la lesión está dada por la sombra acústica que se sobreproyecta a la cortical ósea (Figura 3). Este patrón lo encontramos en 10 de 10 casos de exostosis subungueal (Figuras 4, 5, 6) y en 3 de 12 casos de osteomas y osteocondromas (Figuras 7,8 ).

Ic. Lesión hiperecogénica elevada de superficie irregular.

Lesión hiperecogénica de superficie irregular festoneada con sombra acústica. Es solevantada y la cortical adyacente es regular. No presenta masa de partes blandas adyacentes (Figura 9). Este patrón se encontró solamente en un caso de la serie que correspondió a un hemangioma óseo (Figuras 10 y 11).

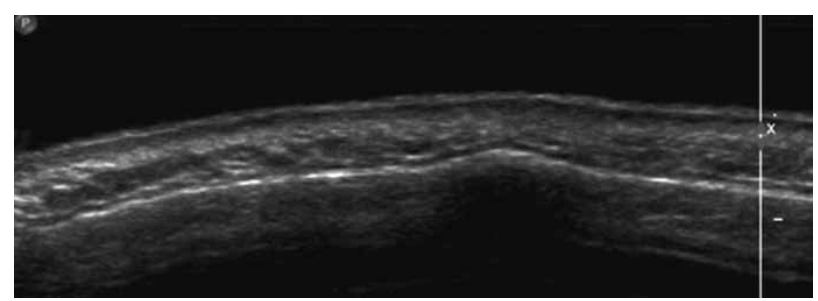

Figura 2. Lesión ósea ecogénica exofítica sugerente de osteoma frontal.

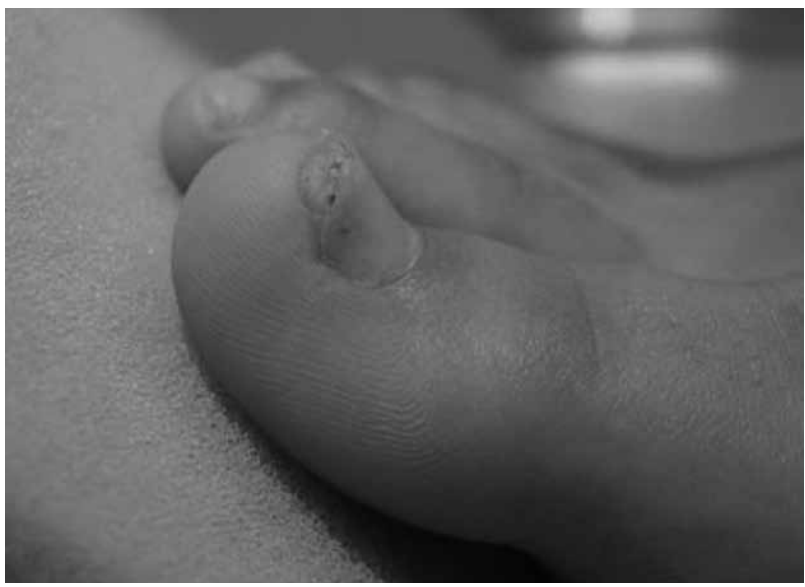

Figura 4. Hombre de 35 años con inflamación del espacio subungueal.

Figura 5. Lesión protruyente con sombra acústica situada en el hueso subungueal. 


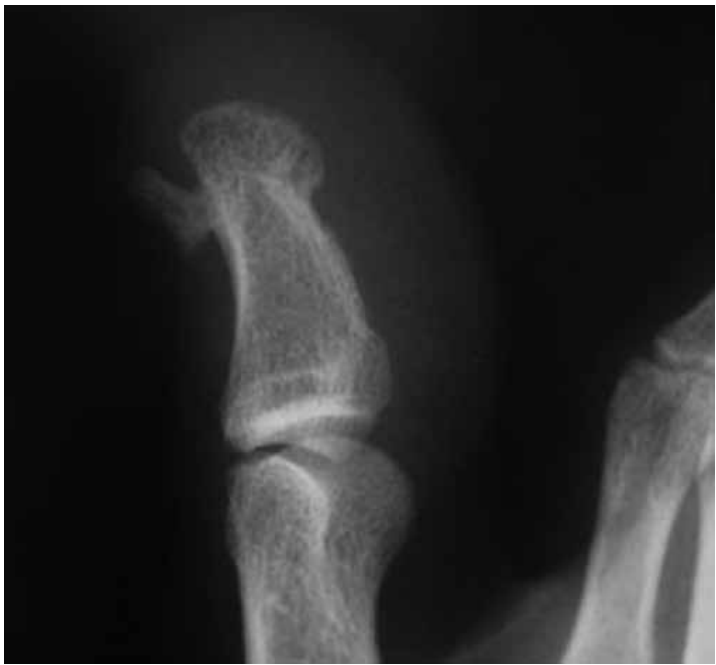

Figura 6. Radiografía lateral de falange que demuestra la apariencia típica de la exostosis.

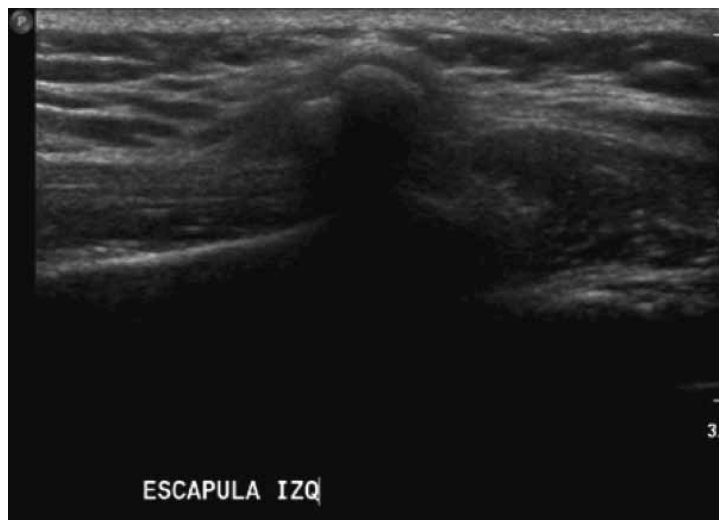

Figura 7. Lesión ósea exofítica situada en la escápula compatible con osteocondroma.

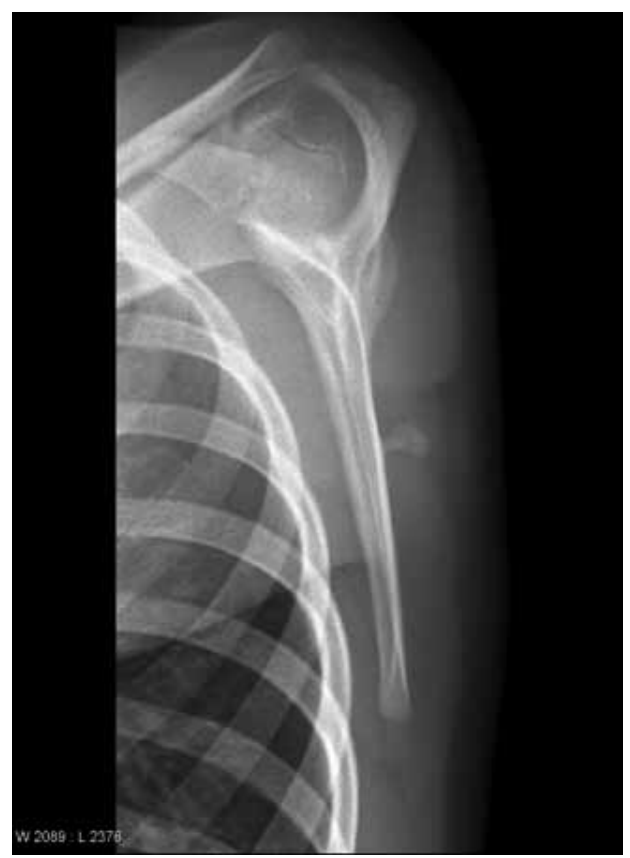

Figura 8. Radiografía convencional demuestra un osteocondroma escapular.

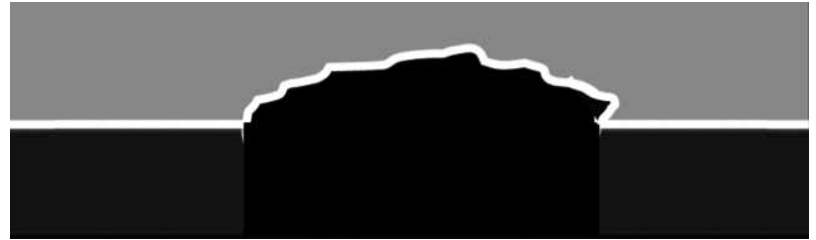

Figura 9. Patrón Tipo Ic. Esquema. Lesión hiperecogénica elevada de ángulos agudos y discreta irregularidad de la superficie ósea.

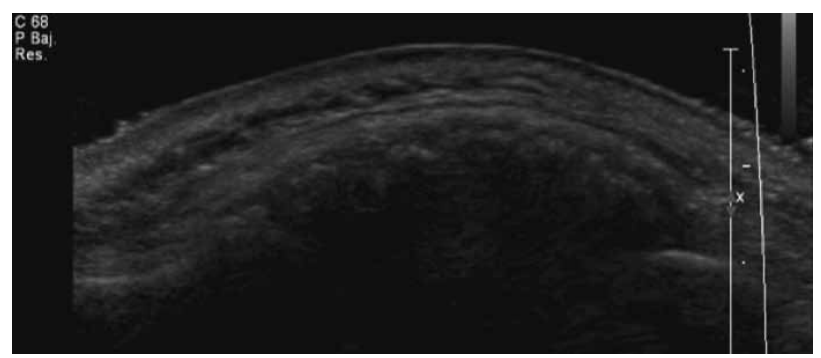

Figura 10. Tumor hiperecogénico exofítico con superficie irregular y ángulos agudos.

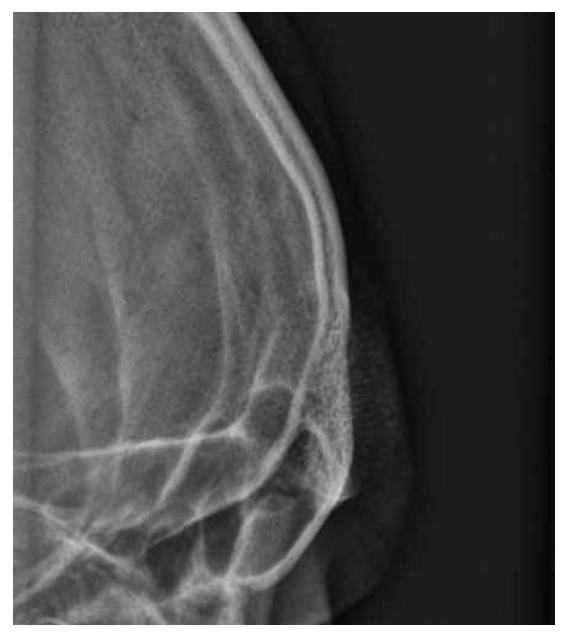

Figura 11. Radiografía localizada del hemangioma de la región frontal de la calota que presenta un patrón trabecular en "panal de abejas" o "rueda de carreta".

\section{TIPO II. Lesión hipoecogénica.}

Il a. Lesión hipoecogénica geográfica sin destrucción cortical ni masa de partes blandas. Correspondió a una lesión expansiva osteolítica bajo la cortical ósea que es regular. No hay masa de partes blandas (Figura 12). Este patrón se encontró solamente en dos casos de lesiones benignas (1 encondroma y 1 tumor pardo) (Figura 13).

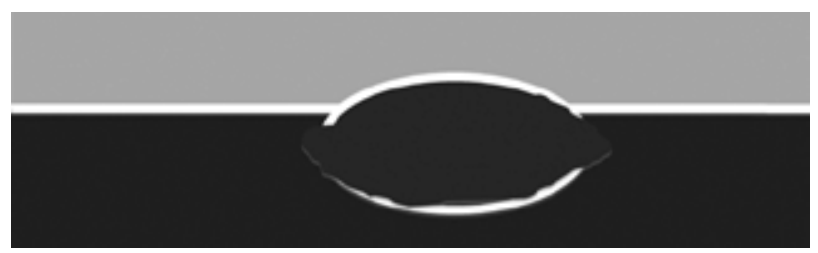

Figura 12. Patrón Tipo Ila. Esquema. Lesión hipoecogénica geográfica sin destrucción cortical ni masa de partes blandas. 
II b. Lesión hipoecogénica con destrucción cortical y masa de partes blandas. Esta lesión presenta un defecto óseo o erosión cortical con aumento de volumen de partes blandas secundaria a una masa de partes blandas, que puede ser vascularizada (Figura 14). Esta forma se presentó en 3 casos, que correspondieron a metástasis (Figuras 15 y 16).

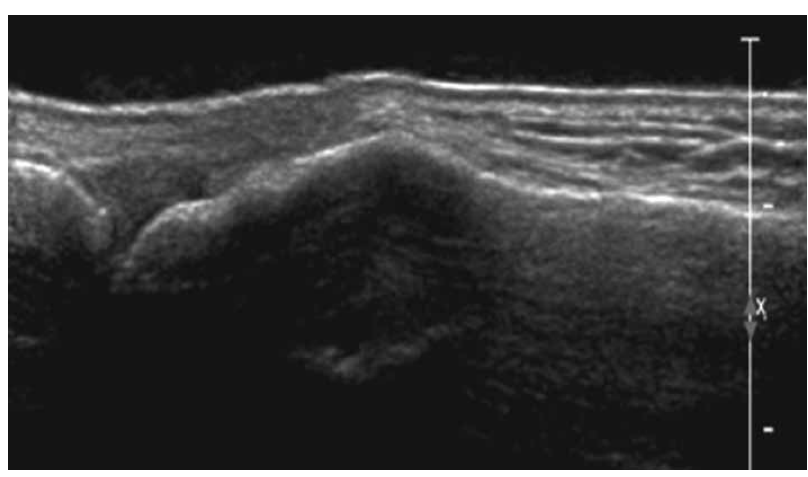

Figura 13. Lesión hipoecogénica subcortical geográfica sin destrucción cortical. El diagnóstico final resultó ser encondroma.

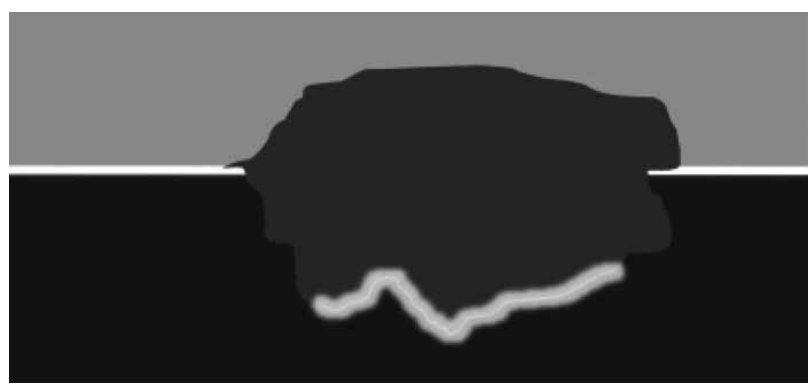

Figura 14. Patrón Tipo Ilb. Esquema. Lesión hipoecogénica con destrucción cortical y masa de partes blandas.

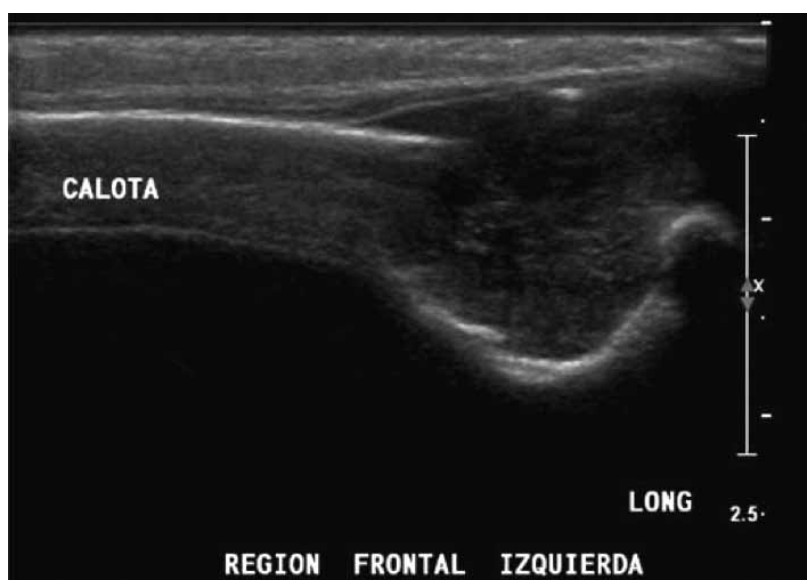

Figura 15. Lesión hipoecogénica con destrucción ósea cortical y masa de partes blandas.

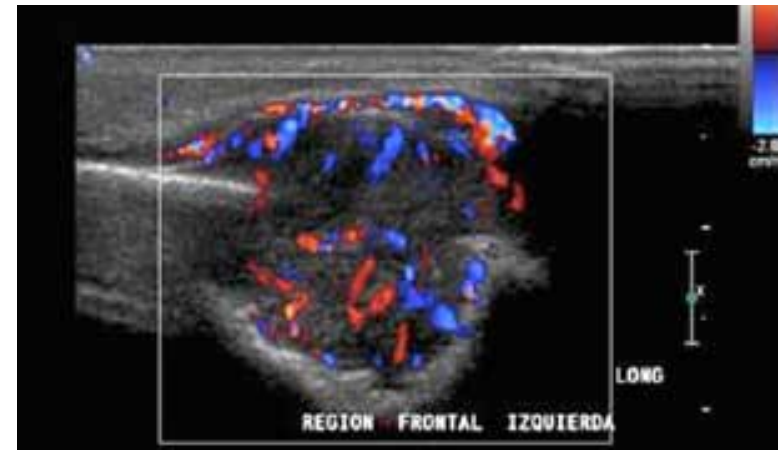

Figura 16. US Doppler color revela una lesión hipervascular, que correspondió a metastasis.

Tipo III. Reacción perióstica irregular o reacción perióstica espiculada tipo "rayo de sol" o "en cabello erizado", masa de partes blandas y superficie ósea irregular. Se presenta como periostitis irregular con cortical ósea irregular y masa de partes blandas, la que puede ser o no vascularizada (Figura 17). Esta forma se presentó en dos casos (un adulto y un niño) que correspondieron a metástasis óseas (Figuras 18, $19,20,21,22,23)$.

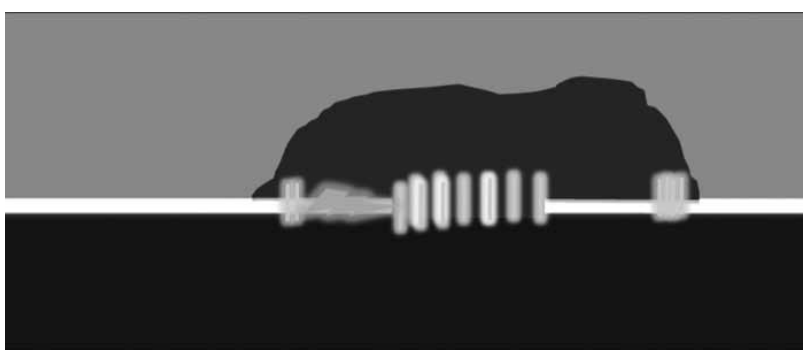

Figura 17. Patrón Tipo III. Esquema. Reacción perióstica irregular tipo "rayo de sol" o "en cabello erizado" y masa de partes blandas.

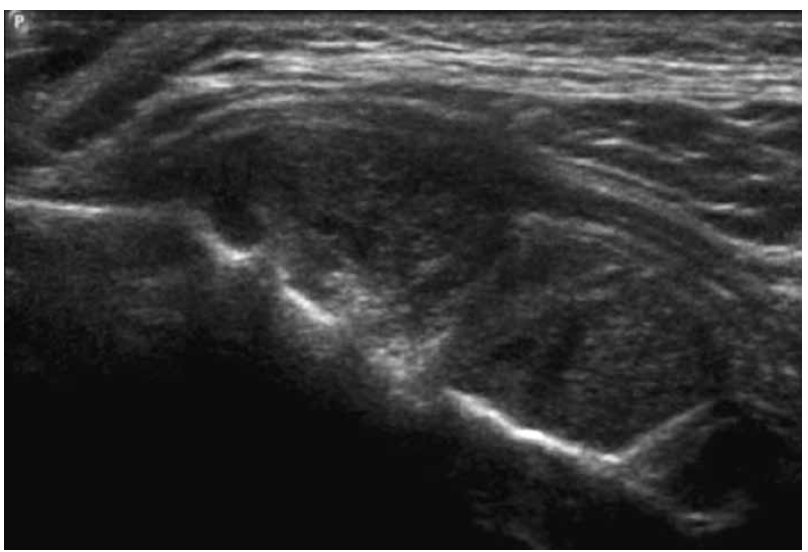

Figura 18. Niño varón de 1 año con inflamación de las partes blandas de la región temporal. EI US demuestra una superficie ósea irregular, con periostitis y masa sólida hipoecogénica. 


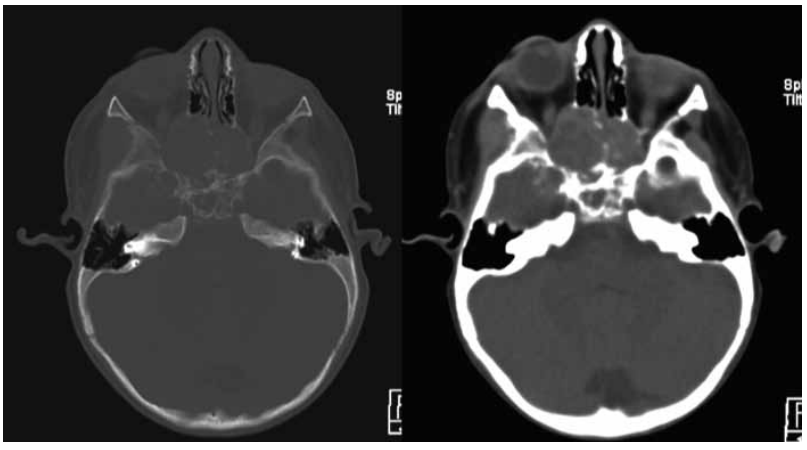

Figura 19. TC axial, ventana oséa y de partes blandas.
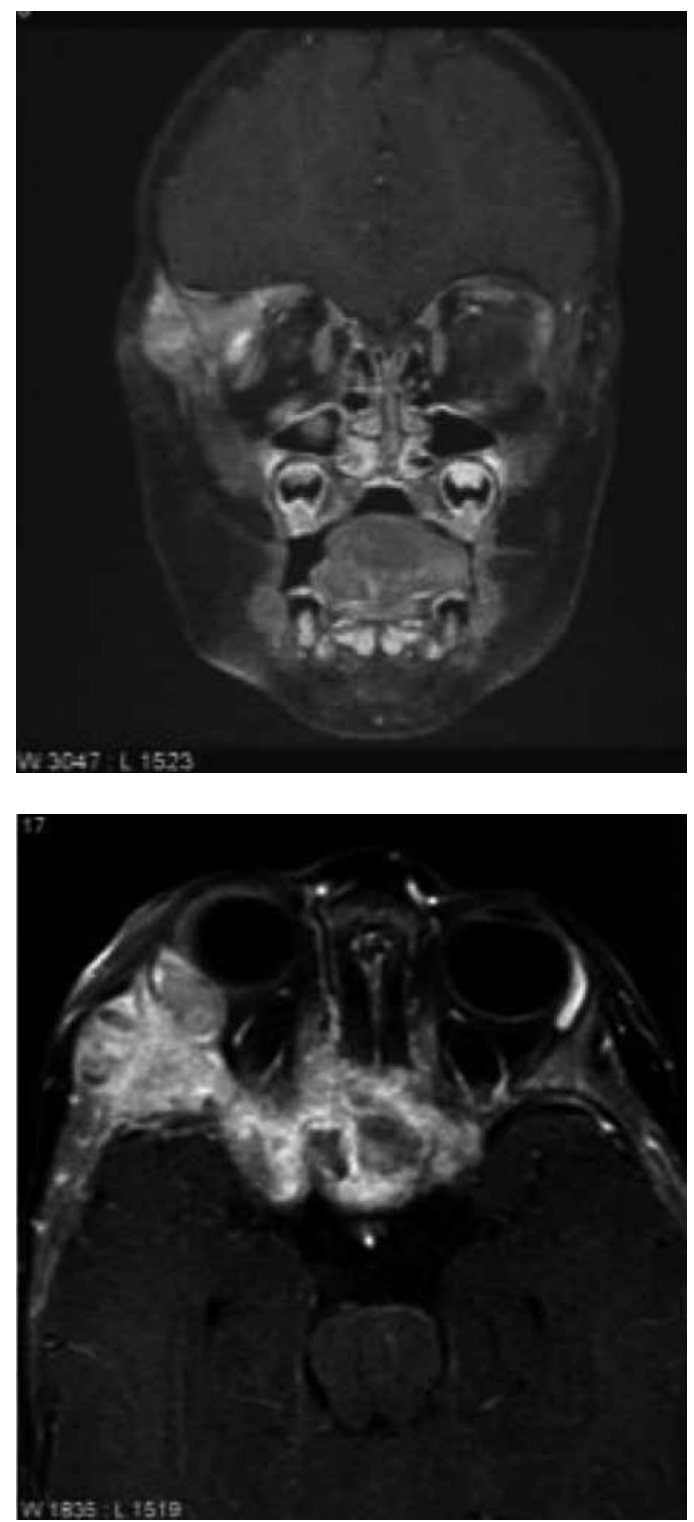

Figura 20, 21. RM con Gadolinio. Se confirma una lesión ósea en la fosa cigomática derecha (flecha), sólida, expansiva, con afectación del tejido subcutáneo que realza intensamente tras la administración del contraste e.v. El estudio con ventana ósea pone de manifiesto una periostitis irregular. La lesión presenta un extenso compromiso esfenoidal y del laberinto etmoidal posterior (asterisco). El resultado histológico confirmó metástasis de neuroblastoma.

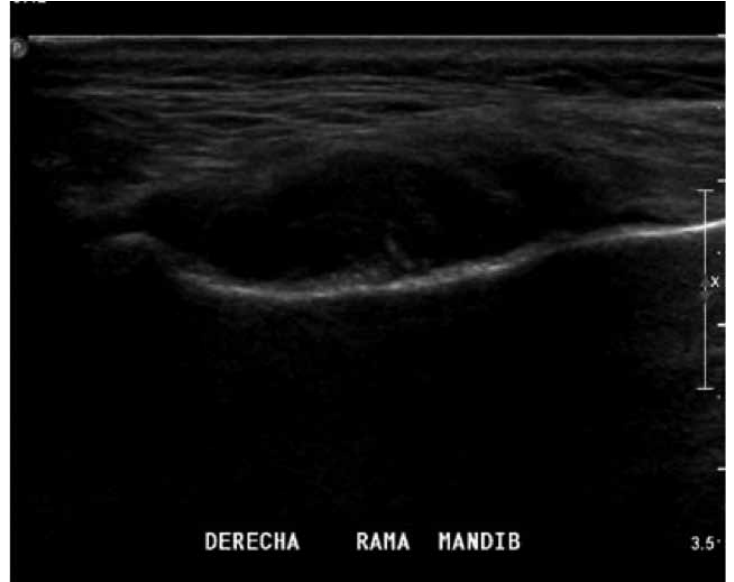

Figura 22. Mujer de 69 años con aumento de volumen maxilar. US demuestra contorno óseo irregular, periostitis irregular y masa sólida.

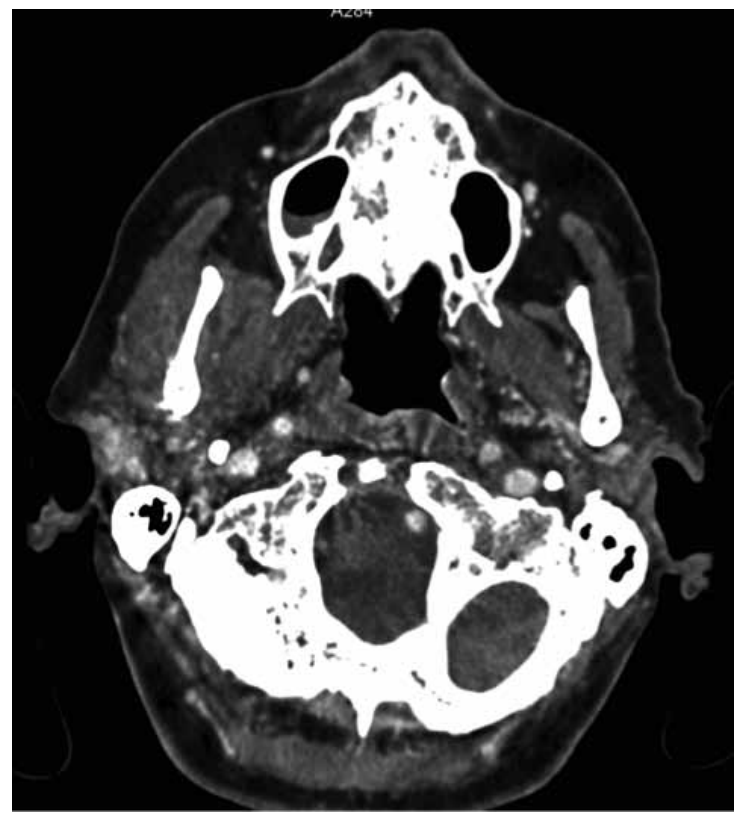

Figura 23. TC muestra un tumor sólido mal definido adyacente al ángulo mandibular, con moderado realce. Biopsia demostró metastásis.

\section{Discusión}

La incidencia exacta de los tumores óseos es desconocida debido a que la mayoría de las lesiones benignas no van a cirugía. Los tumores benignos superan a los malignos con una relación de 5:1 y ellos son mayoritariamente asintomáticos ${ }^{(1)}$. Los tumores benignos son más frecuentes en las tres primeras décadas de la vida, mientras los tumores malignos son más frecuentes en pacientes añosos ${ }^{(3)}$.

Existen signos y síntomas que nos pueden ayudar en el diagnóstico diferencial. El US no es una técnica para diagnosticar lesiones intraóseas y sólo puede ayudar en la identificación ocasional de lesiones óseas que presenten deformación cortical o extensión extraósea. Aun así, puede detectar lesiones tumorales 
óseas no sospechadas clínicamente y ser útil como guía para la realización de biopsias percutáneas ${ }^{(4)}$.

El aumento de volumen de partes blandas como forma de presentación aislada es infrecuente, lo que explica la escasa bibliografía en la literatura médica de hallazgos al US en lesiones óseas tumorales. En un paciente con masa palpable se puede hacer un US de partes blandas como ayuda diagnóstica. En el estudio US por masa palpable es importante visualizar las capas profundas, incluyendo una visión tan profunda como la superficie cortical ósea si no se encuentra la causa del aumento de volumen.

Los tumores óseos en US son descritos en la literatura como una tumoración de partes blandas asociado a un defecto óseo ${ }^{(4)}$. Si la lesión se extiende en la profundidad hacia el hueso, es signo de origen intraóseo. Esta puede presentarse como una lesión sólida hipoecogénica o puede ser heterogénea con áreas anecogénicas por necrosis tumoral. La presencia de líquido puede orientar a un quiste o ganglión óseo y múltiples niveles líquido-líquido a un tumor quístico aneurismático(4).

En nuestra serie se identificaron ciertos patrones ecográficos, hallazgos que pueden ayudarnos en el diagnóstico y en las recomendaciones de cómo seguir en el estudio por imágenes. Las lesiones más frecuentes encontradas en nuestra serie son benignas. Los osteomas, osteocondromas y exostosis subungueales correspondieron al $73 \%$ de los casos.

Los osteomas son lesiones hamartomatosas benignas, de crecimiento lento, compuestas de hueso maduro bien diferenciado ${ }^{(5)}$. Pueden estar localizados en la tabla interna o externa del cráneo. Se encuentran a cualquier edad, con mayor incidencia en la cuarta y quinta década y usualmente son asintomáticas ${ }^{(5)}$. En los estudios por tomografía computada se presentan como una tumoración ósea densa originada de la superficie del hueso, de márgenes netos y sin destrucción ósea(5). La mayoría de nuestros casos se ubicaron en el cráneo, principalmente en el hueso frontal. Por esta localización son fácilmente visibles como aumento de volumen frontal.

Los osteocondromas corresponden al tumor óseo más frecuente, representando el $10-15 \%$ de todos los tumores. Se componen de tejido óseo medular y cortical en continuidad con el hueso subyacente, cubierto de una capa de cartílago hialino. Ecográficamente se observa como una protuberancia metafisiaria ecogénica, cubierta de una capa cartilaginosa hipoecogénica. El US es un buen método para evaluar el grosor de esta capa cartilaginosa, parámetro de gran importancia, ya que un grosor mayor a $1.5 \mathrm{~cm}$, en un esqueleto maduro es sugerente de transformación maligna ${ }^{(6,7)}$.

La exostosis subungueal es generalmente asintomática, pero puede generar un aumento de volumen del espacio subungueal con alteración y desplazamiento de la uña, lo cual es clínicamente visible. Generalmente afecta a los dedos del pie, en especial al hallux. Al US se observa como una estructura hiperecogénica con sombra acústica posterior, inmediatamente bajo la placa ungueal y conectada con el margen óseo de la falange distal ${ }^{(8)}$.

En nuestra serie sólo tuvimos un caso de hemangioma óseo. Este es un tumor benigno de origen vascular, caracterizado por difusión de tejido angiomatoso entre las trabéculas óseas. Tienden a ser asintomáticos. La relación es de 2:1 entre hombres y mujeres y usualmente se descubren entre la cuarta y quinta década de la vida ${ }^{(9)}$. Los hemangiomas craneales corresponden al $20 \%$ de los hemangiomas óseos y comúnmente se localizan en el hueso frontal y parietal $^{(9)}$. Estas son lesiones expansivas que se originan en el diploe y comprometen predominantemente el contorno óseo ${ }^{(10)}$. En rayos X y TC tienen un patrón característico, que consiste en una lesión osteolítica, de borde bien delimitado y con aspecto trabecular llamado distribución en "panal" o "rueda de carreta"(11). No hemos encontrado en la literatura descripción del aspecto US en hemangioma óseo.

Otro caso correspondió a un encondroma. Tumor óseo intramedular común, compuesto por cartílago maduro. Es el segundo tumor óseo benigno en frecuencia y corresponde al 12 a $24 \%$ de los tumores benignos del hueso y a 2 al $10 \%$ de todos los tumores óseos ${ }^{(10,11)}$. En su mayoría son solitarios, pero pueden ser múltiples y asociarse a transformación maligna (20 $-30 \%)^{(11)}$. Estas lesiones tienden a ubicarse en posición metafisiaria o diafisiaria (falanges); y comúnmente afectan las manos, fémur distal y tibia proximal ${ }^{(10)}$. Se presenta entre los 15 y 40 años ${ }^{(10)}$. Usualmente es asintomático, pero se puede presentar con dolor por fractura en hueso patológico. En imágenes se ve como una lesión lítica metafisiaria, geográfica de matriz condroide calcificada en círculos o anillos, pero esto último raramente se ve en las falanges. Ellos pueden producir un borde endóstico irregular y generar expansión ósea ${ }^{(10,12)}$. Al US, la lesión se ha descrito de aspecto similar al cartílago hialino, es decir, homogenea e hipoecogénica, y de contorno bien definido ${ }^{(13)}$.

Las metástasis óseas son la causa más frecuente de lesión ósea maligna. Estas lesiones son 25 veces más comunes que el tumor óseo primario(11). Los sitios más frecuentes de metástasis son el hígado, los pulmones y luego los huesos. Ellas pueden aparecer a cualquier edad, siendo más frecuentes después de la quinta década. Clínicamente se observa baja de peso, dolor, fiebre y en algunos casos masa palpable. En la mayoría de los casos son múltiples y pueden ubicarse en cualquier hueso. Tienen preferencia por el esqueleto axial, con mayor contenido de médula ósea hematopoyética. Su ubicación más frecuente es en columna, costillas, cráneo, fémur y humero proximal ${ }^{(11)}$. La apariencia radiológica es variable, puede ser 
blástica, lítica o ambas. Generalmente de bordes mal definidos y asociado a destrucción cortical, reacción perióstica agresiva o masa de partes blandas ${ }^{(11)}$. Se ha descrito que el US puede detectar una masa de partes blandas originada en el hueso a través de un defecto óseo de la cortical(4).

En nuestra serie, de las lesiones óseas encontradas como aumento de partes blandas al US, observamos que la mayoría eran lesiones benignas (83\%) y correspondieron a osteomas, osteocondromas y exostosis. Ellas se presentaron con el patrón tipo I: lesión hiperecogénica elevada con sombra acústica.

Las lesiones que se presentaron con el patrón tipo Ilb (lesión hipoecogénicas con destrucción cortical y masa de partes blandas) y III (periostitis irregular o reacción perióstica espiculada y masa de partes blandas) fueron todas lesiones agresivas de tipo metastásico.

Las lesiones hipoecogénicas sin destrucción cortical (Ila) correspondieron a lesiones expansivas osteolíticas situadas bajo la cortical ósea que se observa continua y regular.

Hay algunos procesos que deben ser considerados en el diagnóstico diferencial de acuerdo a los patrones descritos. En el tipo I el callo óseo alrededor de una fractura presenta el mismo aspecto ecográfico. Ayuda en el diagnóstico diferencial que no existe antecedente traumático, y que es extremadamente inusual un callo óseo por fractura frontal. También se deben considerar nódulos calcificados de las partes blandas con intensa sombra acústica como pilomatrixomas, en este caso la localización subcutánea es característica de esta entidad.

En las lesiones tipo II y III también se deben considerar erosiones óseas, abscesos, granuloma eosinófilo, osteomielitis y cambios óseos post-traumáticos con calcificaciones paraostales. En estos casos una correcta historia clínica es muy importante.

Hasta la fecha, no hemos encontrado en la literatura médica reportes de los patrones ecográficos 0 hallazgos que puedan orientar hacia la presencia de una lesión ósea tumoral o respecto de su agresividad ${ }^{(14)}$.

Es importante enfatizar que si el US de partes blandas demuestra un origen tumoral, se debe complementar la evaluación con estudio radiológico convencional. En la mayoría de las lesiones benignas permitirá confirmar el diagnóstico y evitará la realización de otros exámenes. En casos aislados sospechosos de metástasis con masa de partes blandas que necesitan de confirmación histológica el US también puede ser una excelente guía para la realización de la biopsia ${ }^{(4,15)}$.

En conclusión, es muy infrecuente que la evaluación ultrasonográfica de un aumento de volumen de partes blandas demuestre una tumoración ósea. Si bien nuestra serie es pequeña, hemos podido reconocer patrones ecográficos que sirvan en el enfrentamiento diagnóstico ante este hallazgo inesperado. Es importante que sepamos reconocer los signos ecográficos que nos permitan una adecuada orientación respecto de la naturaleza de la lesión para así poder guiar en forma eficiente su estudio.

\section{Bibliografía}

1. Holt G., Schwartz H. Bone Tumors (Chapter 32). Townsend C, Beauchamp D, Evers M, Mattox K. Sabiston Textbook of surgery: The Biological Basis of the Modern Surgical Practice. 18 $8^{\underline{a}}$ ed. Philadelphia: Saunders Elsevier 2008.

2. American Cancer Society (2008). Cancer Facts and Figures. 2008. Atlanta, GA: American Cancer Society. Retrieved 2008 March 13.

3. Kumar: Robbins y Cotran: Base patológica de la enfermedad, $7^{\stackrel{a}{a}}$ ed, Copyright $(\odot) 2005$ Saunders. Elsevier. 5 ed. Cap. 27. Pag. 1331-1394.

4. Zamorani M., Valle M.Bone and joint. En Bianchi S., Martinoli C. Ultrasound of the musculoskeletal system. $1^{\text {a }}$ ed. Editorial Springer 2007; 137-185.

5. Greenspan A. Tumores y seudotumores benignos I: Lesiones formadoras de hueso. Greenspan A. Radiología de Huesos y Articulaciones. $2^{\mathrm{a}}$ ed. Editorial Marban 2006; 571-596.

6. Franz T, Leclere F, Rees M. Solitary osteochondroma of the distal radius: A rare cause of carpal tunnel syndrome diagnosed using ultrasound. 2014; 42: 9: 557-559.

7. Mark D. Murphey, James J. Choi, Mark J. Kransdorf, et al. Imaging of Osteochondroma: Variants and Complications with Radiologic-Pathologic Correlation. Radio Graphics 2000; 20(5): 1407-1434.

8. Wortsman X, Wortsman J, Soto R, et al. Benign Tumors and Pseudotumors of the NailJ Ultrasound Med 2010 May; (29): 803-816.

9. Murphey M, Fairbairn J, Parman L, Baxter K, Parsa $M$, Smith S. Musculoskeletal angiomatous lesions: Radiologic-pathologic correlation. Radiographics 1995; 15: 893-917.

10. Greenspan A. Tumores y seudotumores benignos II: Lesiones de origen cartilaginoso. Greenspan A. Radiología de Huesos y Articulaciones $2^{\mathrm{a}}$ ed. Editorial Marban 2006; 597-626.

11. LlaugerRoselló P., Palmer Sancho J. Tumores óseos y lesiones seudotumorales. Del Cura J. L., Pedraza S. y Gayete A. Radiología esencial 1aㅡ ed. Madrid: Editorial Panamericana 2009; 817-833.

12. Murphey M, Flemming D, Boyea S, Bojescul J, Sweet D, Templ T. Enchondroma versus Chondrosarcoma in the appendicular skeleton: Differentiating features. Radiographics 1998; 18: 1213-1237.

13. Wilde G. Adler R. Sonographic evaluation of enchondroma with soft tissue extension in the setting of Ollier disease. J Ultrasound Med 2010 Dec; 29(12): 18491853.

14. Madhusudhan KS, Sharma R, Kandpal H et al. A rare case of combined soft-tissue and intraosseousarteriovenous malformation of the hand with diffuse periosteal elevation: imaging appearances. Br J Radiol 2009 Nov; 82(983): e219-24.

15. Civardi G, Livraghi T, Colombo P, Fornari F, Cavanna L, Buscarini L. Lytic bone lesions suspected for metastasis: Ultrasonically guided fine-needle aspiration biopsy. J ClinUltrasound 1994 Jun; 22(5): 307-311. 